\title{
PENGARUH LATIHAN CURL DUMBLE TERHADAP HASIL SMASH BOLAVOLI SISWA
}

\author{
Oleh : M. Taheri Akhbar \\ (Universitas PGRI Palembang) \\ herideta@gmail.com
}

\begin{abstract}
Abstrak
Masalah dalam penelitian ini dilatar belakangi oleh tidak semua peserta ekstrakurikuler bolavoli dapat melakukan smash dengan sempurna. Oleh karena itu, sebagai salah satu upaya diberikan perlakuan latihan curl dumble. Penelitian ini bertujuan untuk mengetahui pengaruh latihan curl dumble terhadap hasil smash siswa. Metode dalam penelitian ini adalah eksperimen one group desain pretest dan posttest. Dalam penelitian ini terdapat dua variabel, yaitu latihan curl dumble sebagai variabel bebas (X), dan smash bolavoli sebagai variabel terikat (Y). Populasi adalah peserta ekstrakurkuler bolavoli dengan jumlah 28 orang, sedangkan sampel diambil sama dengan jumlah populasi dengan teknik sampling jenuh. Data diperoleh melalui pretest dan posttest smash bolavoli. Data tersebut kemudian dianalisis menggunakan statistik uji-t. Hasil penelitian menyatakan bahwa ada pengaruh latihan curl dumble terhadap hasil smash siswa diterima kebenarannya. Hal ini diperkuat dari hasil pengujian hipotesis dimana $t_{\text {hitung }}>t_{\text {tabel }}$ atau 34,00 $>1,70$, dan rata-rata posttest smash bolavoli lebih baik dibandingkan dengan pretest atau 16,61 > 10,25. Besarnya peningkatan smash bola voli setelah mengikuti latihan curl dumble adalah 6,36. Dengan demikian, latihan curl dumble dapat digunakan untuk meningkatkan smash permainan bolavoli
\end{abstract}

Kata Kunci : Latihan Curl Dumble, Smash Bola voli

\section{THE EFFECT OF CURL DUMBLE TRAINING ON RESULTS OF SMASH BALL VOLLEYBALL STUDENTS}

\begin{abstract}
The problem in this study is that not all volleyball extracurricular participants can smash perfectly. Therefore, as one of the efforts, curl dumble training is given. This study aims to determine the effect of curl dumble exercises on student smash results. The method in this study is a one group experiment pretest and posttest design. In this study there are two variables, namely curl dumble exercise as the independent variable $(X)$, and volleyball smash as the dependent variable (Y). The population is the volleyball extracurricular participants with a total of 28 people, while the sample taken is the same as the population with saturated sampling technique. Data obtained through pretest and posttest smash volleyball. The data is then analyzed using t-test statistics. The results of the study stated that there was an effect of the curl dumble exercise on the students' smash results being accepted. This is reinforced from the results of hypothesis testing where tcount> ttable or 34.00>1.70, and the average volleyball posttest smash is better than pretest or 16.61> 10.25. The magnitude of the increase in volleyball smash after
\end{abstract}

\section{1 | Copyright@HON}


following the curl dumble practice is 6.36 . Thus, curl dumble exercises can be used to improve the volleyball smash game.

Keywords: Curl Dumble Training, Smash Volleyball

Correspondence author: M. Taheri Akhbar, Universitas PGRI Palembang, Indonesia. herideta@gmail.com (c) (i) (2)

Jurnal Halaman Olahraga Nusantara licensed under a Creative Commons Attribution-ShareAlike 4.0 International License.

\section{PENDAHULUAN}

Bolavoli merupakan salah cabang permainan bola besar yang dimainkan oleh dua tim yang saling berlawanan di dalam sebuah lapangan dan dibatasi oleh net antara tim. Hal ini sebagaimana yang dikemukakan Sutanto (2016)bahwa "bolavoli olahraga yang dimainkan oleh dua tim berlawanan. Masing-masing tim memiliki enam orang pemain. Olahraga ini dimainkan dengan memantulkan bola dari tangan ke tangan, selanjutnya bola tersebut dijatuhkan ke daerah lawan. Tim lawan yang tidak bisa mengembalikan bola dianggap kalah dalam permainan.

Permainan bolavoli pada umumnya dimainkan oleh semua masyarakat, yaitu dari instansi pemerintah, swasta, lingkungan masyarakat yang mulai dari anak-anak, orang dewasa, pria maupun wanita. Awal permainan bolavoli dimulai dengan bola di service ke arah lapang lawan dengan bola melewati arah atas net dan bola jatuh ke arah tim lawan, bola diambil dengan menggunakan kedua tangan kemudian bola tersebut diberikan kearah pengumpan dan kemudian pengumpan melambungkan bola ke atas net kemudian bola tersebut langsung di smash ke arah lapangan lawan agar menjadi poin, secara bersamaan tim lawan melakukan bendungan agar bola tersebut tidak melewati lapangannya. Dalam permainan Bolavoli tentunya para pemain harus mempunyai kecakapan yang baik sehingga bisa mencapai prestasi. Untuk memiliki kecakapan khusus para pemain tidak terlepas dari latihan-latihan, baik itu latihan secara fisik maupun teknik.

Penelitian ini dilaksanakan pada salah satu program kegiatan ekstrakurikuler bolavoli. Berdasarkan hasil observasi awal bahwa tidak semua peserta ekstrakurikuler bolavoli dapat melakukan smash dengan sempurna. Selain itu juga, posisi tangan saat memukul bola masih belum tepat, sehingga smash

\section{2 | Copyright@HON}


yang dilakukan hanya sekedar untuk melewatkan bola yang dipukul dari net. Hal ini dikarenakan kurangnya konstribusi kekuatan otot lengan siswa, sehingga bola yang dipukul tidak keras (tajam) dan lambat. Oleh karena itu, sebagai salah satu upaya untuk meningkatkan ketepatan dan kecepatan bola saat dipukul adalah dengan metode latihan curl dumble. Latihan ini lebih fleksibel dan hampir dapat digunakan dalam pembentukan setiap otot khususnya otot lengan, dapat digunakan dari pembentukan otot bagian atas hingga otot bagian bawah. Selain itu juga, latihan curl dumble dapat dilakukan dengan berbagai variasi, seperti duduk, berdiri dan berbaring sehingga banyak otot di bagian lengan yang telatih, Dengan demikian, diharapkan dengan latihan curl dumble dapat meningkatkan kekuatan otot lengan, sehingga lebih lanjut dapat menunjang pemain dalam melakukan pukulan smash permainan bolavoli. Dugaan ini selaras dengan hasil penelitian Saman (2017) bahwa latihan curl dumble memberikan pengaruh yang signifikan terhadap kemampuan smash pada permainan bolavoli.

\section{METODE}

Rancangan pada penelitian ini menggunakan eksperimen one disign group pretest-posttest. Menurut Sugiyono (2011) bahwa disigen group pretest-posttest merupakan desain yang memberikan pretest sebelum diberikan perlakuan. Dengan demikian hasil perlakuan dapat diketahui lebih akurat, karena dapat membandingkan dengan keadaan sebelum diberi perlakuan.

Teknik pengumpulan data dalam penelitian ini adalah tes smash permainan bolavoli. Menurut Sugiyono (2010) bahwa dalam penelitian kuantitatif, analisis data merupakan "kegiatan setelah data dari seluruh responden atau sumber data lain terkumpul". Analisis data dilakukan menggunakan Uji t.

Populasi adalah keseluruhan subjek penelitian Arikunto (2015). Pendapat yang sama dikemukakan Sugiyono (2010), “populasi adalah wilayah generalisasi yang terdiri atas, objek atau subyek yang mempunyai kualitas dan karakteristik tertentu yang ditetapkan oleh peneliti untuk dipelajari dan kemudian ditarik kesimpulannya". Populasi dalam penelitian ini adalah siswa dengan jumlah 28

\section{3 | Copyright@HON}


orang.

Menurut Sugiyono (2010), "sampel adalah bagian dari jumlah dan karakteristik yang dimiliki oleh populasi tersebut". Sampel dalam penelitian ini diambil menggunakan teknik sampling jenuh. Menurut Sugiyono (2010), "sampling jenuh merupakan teknik penentuan sampel bila semua populasi digunakan sebagai sampel". Hal ini sering dilakukan bila jumlah populasi relatif kecil, kurang dari 30. Dengan demikian, seluruh populasi dijadikan sampel penelitian yang berjumlah 28 orang.

\section{HASIL DAN PEMBAHASAN}

Smash peserta ekstrakurikuler bolavoli dilakukan sebanyak 5 kali kesempatan. Penilaian terdiri dari dua bagian yang tidak terpisahkan, angka sasaran ditambah waktu dari kecepatan jalannya bola. Data hasil tes tersebut diperoleh skor tertinggi 135,3 dan skor terkecil 72,9, sehingga rentang dari hasil tes tersebut adalah 62,4 .

Tabel 1. Dsitribusi Frekuensi Pre-test

\begin{tabular}{|c|c|c|}
\hline Kelas Interval & Frekwensi Absolut & Frekwensi Relatif (\%) \\
\hline $72,9-83,3$ & 6 & 21,43 \\
\hline $83,4-93,8$ & 4 & 14,29 \\
\hline $93,9-104,3$ & 9 & 32,14 \\
\hline $104,4-114,8$ & 2 & 7,14 \\
\hline $114,9-125,3$ & 5 & 17,86 \\
\hline $125,4-135,8$ & 2 & 7,14 \\
\hline Jumlah & $\mathbf{2 8}$ & $\mathbf{1 0 0 , 0 0}$ \\
\hline
\end{tabular}

Tabel 1 di atas, menyatakan bahwa terdapat 6 siswa $(21,43 \%)$ memperoleh skor pada interval 72,9 - 83,3; 4 siswa (14,29\%) mendapatkan skor pada interval $83,4-93,8,9$ siswa $(32,14 \%)$ pada interval 94,9-104,3; 2 siswa $(7,14 \%)$ pada interval 104,4 - 114,8; 5 siswa (17,86\%) pada interval 114,9 125,4; dan 2 siswa $(7,14 \%)$ pada interval 125,4 - 135,8. Selain itu juga, deskripsi data pretest dapat dilihat pada gambar berikut.

\section{4 | Copyright@HON}




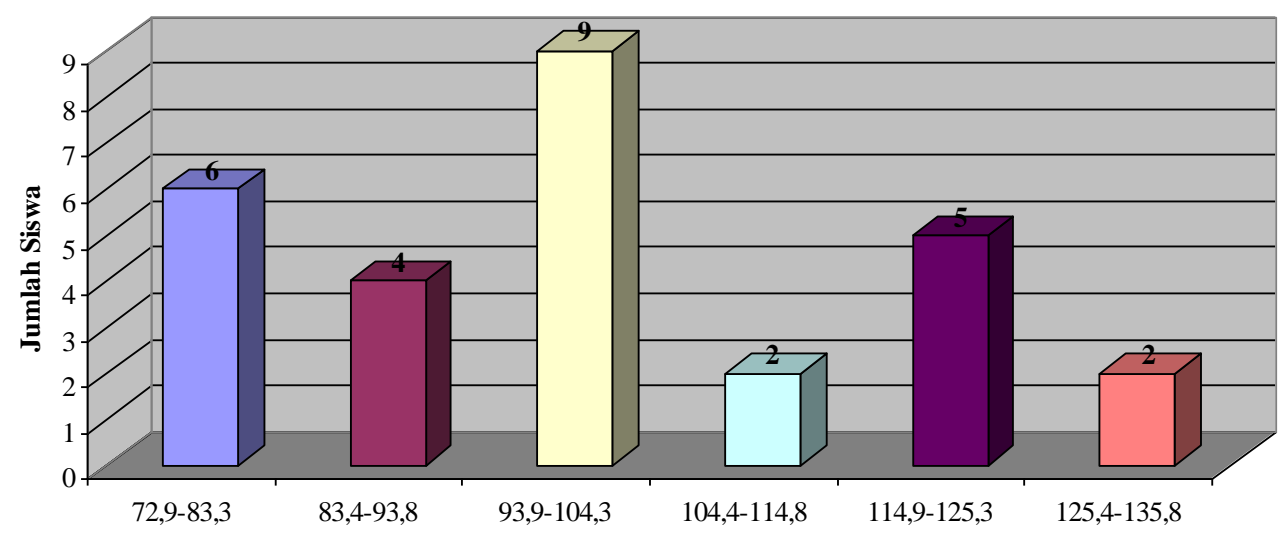

Gambar 1. Diagram Pre-test Smash Bolavoli

Hasil post-test smash bolavoli diperoleh skor tertinggi 134,0 dan skor terkecil 63,9, sehingga rentang dari hasil tes tersebut adalah 70,1. Perhitungan sama halnya pada data pretest, sehingga diperoleh hasil pada tabel berikut.

Tabel 2. Distribusi Frekuensi Posttest Smash Bolavoli

\begin{tabular}{|c|c|c|}
\hline Kelas Interval & Frekuensi Absolut & Frekeunsi Relatif (\%) \\
\hline $63,9-75,5$ & 3 & 10,71 \\
\hline $75,6-87,2$ & 6 & 21,43 \\
\hline $87,3-98,9$ & 4 & 14,29 \\
\hline $99,0-110,6$ & 6 & 21,43 \\
\hline $110,7-122,3$ & 5 & 17,86 \\
\hline $122,4-134,0$ & 4 & 14,29 \\
\hline Jumlah & $\mathbf{2 8}$ & $\mathbf{1 0 0 , 0 0}$ \\
\hline
\end{tabular}

Tabel 2 di atas, menyatakan bahwa terdapat 3 siswa (10,71\%) memperoleh skor pada interval $63,9-75,5 ; 6$ siswa $(21,43 \%)$ mendapatkan skor pada interval 75,6 - 87,2; 4 siswa $(14,29 \%)$ pada interval 87,3 - 98,8; 6 siswa $(21,43 \%)$ pada interval 99,0 - 110,6; 5 siswa $(17,86 \%)$ pada interval 110,7 - 122,3; dan 4 siswa $(14,29 \%)$ pada interval $122,4-134,0$. Selain itu juga, deskripsi data posttest dapat dilihat pada gambar berikut. 


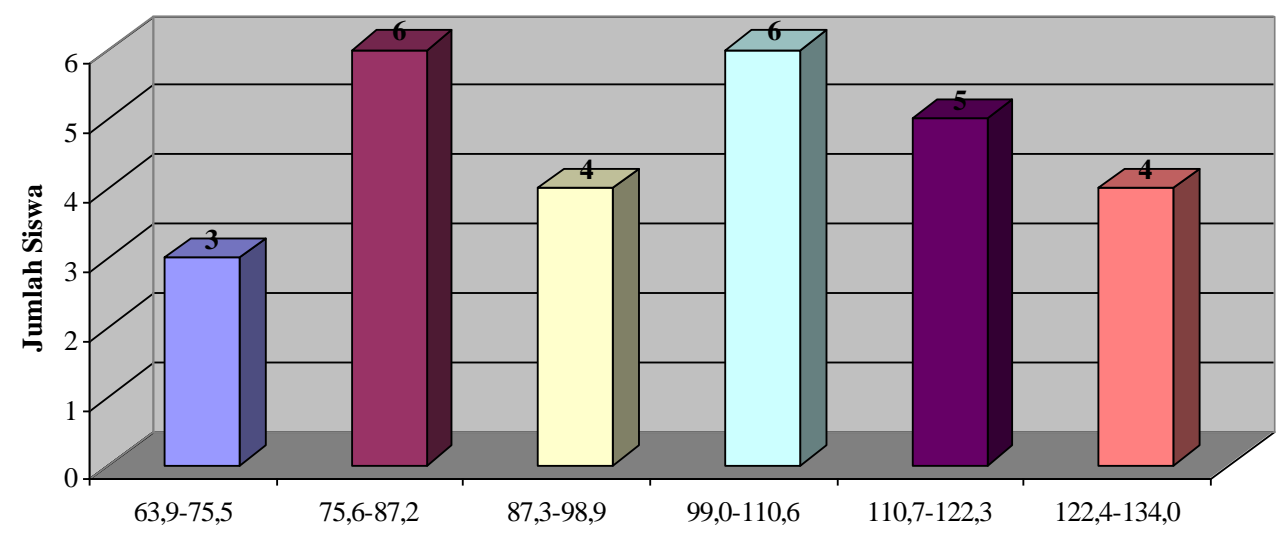

Gambar 2. Diagram Posttest Smash Bolavoli

Analisis data dalam penelitian ini meliputi pengujian normalitas data, dan pengujian hipótesis.

Uji normalitas data merupakan syarat yang harus dipenuhi sebelum pengujian hipotesis dilakukan. Data yang diuji adalah hasil pretest dan posttest smash semi bolavoli siswa menggunakan uji Liliefors, yang hasilnya dapat dilihat pada tabel berikut.

Tabel 3. Hasil Pengujian Normalitas Data

\begin{tabular}{|c|l|c|c|c|c|}
\hline No & Tes & N & Lhitung & Ltabel & Keterangan \\
\hline 1 & Pretest & 28 & 0,1072 & 0,1674 & Normal \\
\hline 2 & Posttest & 28 & 0,0985 & 0,1674 & Normal \\
\hline
\end{tabular}

Tabel di atas, menunjukkan nilai Lhitung pretest sebesar 0,1072 dan Lhitung posttest sebesar 0,0985 sedangkan Ltabel dengan $\mathrm{N}=28$ sebesar 0,1674. Berdasarkan kriteria pengujian normalitas, dinyatakan Lhitung < Ltabel. Dengan demikian, data pretest dan posttest smash permainan bolavoli berdistribusi normal.

Setelah data dinyatakan berdistribusi normal, maka selanjutnya dilakukan uji hipotesis dengan menggunakan uji-t. Hasil pengujian hipotesis dinyatakan pada tabel berikut.

\section{6 | Copyright $\bigcirc$ HON}


Tabel 4. Hasil Pengujian Hipotesis

\begin{tabular}{|c|l|c|c|c|c|c|}
\hline No & Tes & $\mathbf{N}$ & $\bar{X}$ & $\mathfrak{t}_{\text {hitung }}$ & $\mathfrak{t}_{\text {tabel }}$ & Keterangan \\
\hline 1 & Pretest & 28 & 10,25 & \multirow{2}{*}{34,00} & 1,70 & Ha diterima \\
\cline { 1 - 3 } 2 & Posttest & 28 & 16,61 & & & \\
\hline
\end{tabular}

Tabel di atas, menyatakan bahwa thitung $>$ ttabel atau 34,00 >1,70, maka tolak Ho dan terima Ha, berarti hipotesis yang berbunyi ada pengaruh latihan curl dumble terhadap hasil smash siswa diterima kebenarannya

\section{PEMBAHASAN}

Berdasarkan analisis data yang telah diuraikan, dapat diketahui bahwa latihan curl dumble telah diberikan pada siswa berdasarkan prinsip-prinsip latihan, yaitu kesiapan, individual, beban berlebih, peningkatan, kekhususan, variasi, pemanasan dan pendinginan, latihan jangka panjang, multilateral, dan prinsip partisipasi aktif berlatih. Selain itu juga, siswa dalam mengikuti latihan dengan bersungguh-sungguh, dalam artian benar mengikuti latihan. Meskipun kondisi fisik khususnya curl dumble menjadi prioritas utama saat mengikuti latihan. Latihan curl dumble dapat dilakukan dengan baik dan benar sesuai dengan arahan peneliti. Hal ini dapat dilihat dari aktivitas siswa sewaktu latihan dalam setiap pertemuan selalu serius mengikuti latihan yang diberikan.

Latihan curl dumble menurut Armswing dikutip Saman (2017) bahwa latihan curl dumble merupakan latihan yang menggunakan dumble atau beban sebagai alat latihan. Latihan ini bertujuan untuk mengembangkan kemampuan dinamis lokal ekstensi dan fleksi otot lengan, bahu dan punggung serta meningkatkan daya eksplosif pada otot lengan bahu.

Berdasarkan hasil penelitian, dinyatakan bahwa rata-rata posttest smash bolavoli lebih baik dibandingkan dengan pretest atau 16,61 >10,25, sedangkan hasil pengujian normalitas dinyatakan bahwa data berdistribusi normal, dan pengujian homogenitas data dinyatakan homogen. Selanjutnya dapat dilakukan pengujian hipotesis menggunakan statistik "uji-t". Kriteria pengujian hipotesis

\section{7 | Copyright@HON}


terima Ho jika thitung $<\operatorname{ttabel}(1-\alpha)$ dan tolak Ho jika thitung $>\operatorname{ttabel}(1-\alpha)$ dimana $\mathrm{t}(1-\alpha)$ didapat dari tabel distribusi $\mathrm{t}$ dengan $\mathrm{dk}=\mathrm{n}-1$, untuk thitung $=$ 34,00 , sedangkan untuk $\mathrm{t}$ tabel $=1,70$, jadi thitung $>$ ttabel atau 34,00 $>1,70$, maka tolak Ho dan terima Ha, berarti hipotesis yang berbunyi ada pengaruh latihan curl dumble terhadap hasil smash siswa diterima kebenarannya. Adanya pengaruh tersebut selaras dengan pendapat Irianto (2006) , bahwa latihan adalah proses sistematis menggunakan gerakan bertujuan meningkatkan atau mempertahankan kualitas fungsi tubuh yang meliputi kualitas daya tahan parujantung, kekuatan dan daya tahan otot, kelentukan, dan komposisi tubuh. Hasil penelitian ini juga selaras dengan studi Saman (2017), bahwa latihan curl dumble terhadap kemampuan smash pada permainan bolavoli siswa SMAN 6 Kendari.

\section{KESIMPULAN}

Berdasarkan analisa data hasil penelitian dapat disimpulkan bahwa ada pengaruh latihan curl dumble terhadap hasil smash siswa diterima kebenarannya. Hal ini diperkuat dari hasil pengujian hipotesis dimana thitung > ttabel atau $34,00>1,70$, dan rata-rata posttest smash bolavoli lebih baik dibandingkan dengan pretest atau 16,61 > 10,25. Besarnya peningkatan smash bola voli setelah mengikuti latihan curl dumble adalah 6,36. Dengan demikian, latihan curl dumble dapat digunakan untuk meningkatkan smash permainan bolavoli.

\section{DAFTAR PUSTAKA}

Arikunto, Suharsimi. 2015. Prosedur-Prosedur Penelitian. Jakarta: RinekaCipta Ahmad, Susanto.

Irianto, DP. 2006. "Bugar Dengan Sehat Berolahraga.... - Google Cendekia.”

Saman, A. 2017. "Pengaruh Latihan Curl Dumble Terhadap Kemampuan Smash Pada Permainan Bolvoli Siswa SMA N 6 Kendari. Jurnal Ilmu Keolahragaan." 16((2) Juli-Desember).

Sugiyono, Prof Dr. 2010. "Metode Penelitian Pendidikan." Pendekatan Kuantitatif.

\section{8 | Copyright@HON}


M Taheri Akhbar, (2020)

Pengaruh Latihan Curl Dumble Terhadap Hasil Latihan Smash Bola Voli Siswa

Sugiyono. 2011. Metode Penelitian Pendidikan Pendekatan, Kuantitatif, Kualitatif dan R\& D. Bandung: Alfabeta.

Sutanto, T. 2016. Buku Pintar Olahraga. Yogyakarta: Pustaka Baru Press. 